\title{
Beyond Business as Usual: What Might 3-D Wellbeing Contribute to MDG Momentum?
}

\author{
Allister McGregor and Andy Sumner
}

\begin{abstract}
The Millennium Declaration provided considerable impetus to refocus the efforts of development agents around the world on the major ethical challenge of eradicating global poverty. The MDGs that followed have become an important mechanism for pursuing the agenda of the Millennium Declaration. We are now, however, at a point where reflection on the MDG framework is called for. In this article we explore what the contribution of a concept of (3-dimensional) wellbeing might bring to a revived MDG momentum.
\end{abstract}

\section{Introduction \\ In this article we explore what new thinking on the concept of (3-dimensional) human wellbeing might bring to a revived Millennium \\ Development Goal (MDG) momentum. In part, the call for reflection on the MDGs (noting the 2010 MDG review) arises from the fact that as we get closer to the 2015 MDG Target year, it has become clear that the ambitious Goals set will likely not be achieved in all developing countries (Bourguignon et al. 2009). And even where targets might nominally be reached, it is not always clear that the quality of poverty reduction is evident. ${ }^{1}$ Moreover, the recent global crises of food, fuel and finance, which developing countries have been bearing the brunt of, are making it all the more difficult for some countries to achieve their MDG Targets. These factors conspire to generate concern for the political momentum of the Millennium Declaration agenda. It is possible that the perceived failure of the MDG process will cause the dissipation of the international political and policy focus on poverty reduction that has been a major benefit of the Millennium Declaration.}

At the same time, however, there is a broad range of initiatives on a global scale which are focusing on rediscovering the significance of the concept of wellbeing for how we think about, measure and do 'development'. This has involved major scholarly contributions to debates (e.g. Sen 1999; Kahneman et al. 2003; Layard 2006); specific research initiatives (the Wellbeing in Developing Countries programme, ${ }^{2}$ the Oxford Poverty and Human Development Initiative and the United Nations University WIDER Frontiers of Poverty Analysis programme); and global movements for the reform of some of the major elements of international development thinking (such as the OECD Measuring Progress Project, and the Sarkozy Commission).

All of these initiatives are motivated by recognition of the shortcomings in currently dominant modes of how we think about and measure societal development. The Sarkozy Commission, chaired by Amartya Sen, Joseph Stiglitz and Jean-Paul Fitoussi, provides the strongest signpost of all. A key message of its final report (Sarkozy Commisison (Stiglitz, Sen and Fitoussi) 2009: 10), is that there is a need 'to shift emphasis from measuring economic production to measuring people's wellbeing'. This is based on a recognition that the measurement of income as a proxy for societal development and progress has tended to shape the kinds of policy we develop, but that the challenges that we currently face globally require a different kind of policy approach. 
Table 1 3-D wellbeing: dimensions, areas of study and indicators

\begin{tabular}{|c|c|c|c|}
\hline Dimensions of wellbeing & Material & Relational & Subjective \\
\hline What is to be studied & $\begin{array}{l}\text { The objectively observable } \\
\text { outcomes that people are } \\
\text { able to achieve }\end{array}$ & $\begin{array}{l}\text { The resources that a person } \\
\text { is able to command and } \\
\text { the extent to which they } \\
\text { are able to engage with } \\
\text { others in order to achieve } \\
\text { their particular needs and } \\
\text { goals }\end{array}$ & $\begin{array}{l}\text { The meanings that people } \\
\text { give to the goals they achieve } \\
\text { and the processes in which } \\
\text { they engage }\end{array}$ \\
\hline Indicators & $\begin{array}{l}\text { Needs satisfaction } \\
\text { indicators. (Take, e.g. the } \\
\text { target for MDG } 1 \text { on child } \\
\text { malnutrition) }\end{array}$ & $\begin{array}{l}\text { Material asset indicators. } \\
\text { Multidimensional resource } \\
\text { indicators. Human agency } \\
\text { indicators. (Take, e.g. the } \\
\text { gender empowerment } \\
\text { Target of MDG 3) }\end{array}$ & Quality-of-life indicators \\
\hline
\end{tabular}

These shortcomings of too narrow a conception of human and societal development suggest that pro-poor policy also needs rethinking because the same income-focused framings of poverty have shaped policy responses to it.

In this article, we argue that there have been benefits from the MDG experience and processes (for further discussion of these, see Manning in this IDS Bulletin) and that they provide lessons that can be built upon. Here we are concerned to review how the conceptual foundations of the MDGs might be strengthened to achieve the professed desire for focus and coherence for effective poverty reduction efforts.

\section{What is ' 3 -D human wellbeing'?}

The study of human wellbeing has a long history and the social approach to human wellbeing that is outlined here draws upon and synthesises various traditions (see McGregor 2007 for discussion). It builds on Amartya Sen's focus on 'beings' and 'doings' in the human development approach, but combines it with insights from other academic traditions in social anthropology, social psychology, livelihoods frameworks, and participatory development to focus on the interactions between beings, doings and feelings. Robert Chambers' emphasis on the need for the development profession to listen to the voices of poor people and to their perceptions and feelings about poverty was particularly influential in shaping the notion of 3-D human wellbeing.
Human wellbeing, we argue, can be conceived of in terms of the interplay of three dimensions: the material, the relational and the subjective (also referred to as perceptual). If we reverse the notion of wellbeing to explore the problem of how poverty is generated and reproduced, we find that conventionally it has been understood in terms of material deprivation; latterly the social exclusion and capital literatures have emphasised the importance of relationships; and here a third dimension of subjective experiences and feelings is added to the framework. Studies of development and poverty that have closely engaged with the reality of people's day-to-day lives have long pointed out that people's own aspirations and experience of life matter in how they conceive of and struggle for wellbeing (e.g. Lewis 1996, Appadurai 2004). From this 3-D wellbeing perspective, all three dimensions must be understood as interacting with each other; however, traditional, disciplinary social science approaches to development have tended to take these different dimensions of people's lives apart to study them in isolation from each other. The 3-D wellbeing framework reunites these components conceptually and in a methodology for how we might understand and generate measurements of human progress. If development policy, and poverty policy in particular, is intended to generate forms of intervention that are genuinely supportive of people's struggles for wellbeing, then all three of these dimensions and the relations between 
them must be taken into account. In Table 1 we outline the three dimensions, indicate what those dimensions imply for what must be researched and suggest the types of indicators that are relevant to each dimension.

A 3-D human wellbeing approach requires the already widely accepted shift of focus beyond incomes, but also further beyond the position advocated by the human development framework, to adopt an approach with a more rounded account of what people can do and be, and how they evaluate what they can do and be. This implies that policy intended to stimulate meaningful development progress is not realistic if it focuses on just one or two of the dimensions to the exclusion of the other(s): the relationship between all three dimensions must be taken into account. Currently, the 'business as usual' approach to development policy tends to emphasise the first dimension and underplay or ignore the second and third dimensions of this way of conceiving of human wellbeing. In part this is because, as the Sarkozy Commission observes, the conceptual models and measures that address the material dimensions of wellbeing are the best developed and are well tailored to the structures of policy deliberation and implementation. The 3-D wellbeing approach, however, argues that if progress on sustainable poverty reduction is to be achieved then it is necessary to go beyond 'business as usual' and seek to address the ways in which the relational and subjective dimensions of people's lives matter for how poverty is generated and reproduced.

A brief reflection on what this 3-D conception has to say to the analysis of child wellbeing is illustrative of the value of this approach and is appropriate since the MDGs are largely focused on children - child nutrition, child education and child health. It is also an important illustration of its significance for policy thinking because children account for an average of 37 per cent of the population in developing countries, and 49 per cent of the population in the least developed countries (UNICEF 2005: 12). ${ }^{3}$

Standard material and human indicators of child development are important but they do not capture much of whether in a particular society children are flourishing to be the strong and mature adults that future development will depend upon. Increasingly however, as agencies have engaged with children's own voices, a broader agenda has emerged. UNICEF, for example, has noted that perceptions of peace in society, perceived family harmony, perception of the health of their environment, quality of food, access to schooling, ability to play in safety and the degree to which they are 'looked down on' by others are all important to children (Redmond 2008). In Redmond's review of research with children, he notes that although adults (and inter alia policymakers) emphasise the material wellbeing of children, when asked, children drew attention to the relational aspects of wellbeing in particular:

what concerns children is not lack of resources per se, but exclusion from activities that other children appear to take for granted, and embarrassment and shame at not being able to participate on equal terms with other children. (Redmond 2008: 12)

None of this suggests that child nutrition and health, or education levels achieved are not important but a 3-D wellbeing approach highlights the unavoidable significance of the relational and subjective dimensions of wellbeing for the development of healthy and socially confident children. In this way a 3-D human wellbeing approach provides value-added over the 'traditional poverty' focus and also points to the importance of areas for policy consideration that have hitherto been considered fringe, flaky or marginal.

By explicitly integrating relational and subjective perspectives with the material dimension the 3-D wellbeing agenda urges development policy and practice to find ways to move beyond 'business as usual'. Recognising that the material, relational and subjective dimensions of our lives are co-evolving, interdependent and dynamically interacting, it encourages a positive perspective on development and poverty reduction policy. It proposes a more respectful view of the rounded humanity of all people and is focused on what people can do, can be and feel, rather than on the deficits in what they have and can do. This sets a different agenda for development policy, which warns against externally and paternalistically defined and imposed notions of wellbeing, and rather calls for the profound integration of self-determination and 
participation. In line with Nancy Fraser's work on recognition and respect, it avoids the 'othering' of people as the 'poor' thus separating them from and casting them as inferior to the 'non-poor' in policy deliberations.

\section{Goal displacement and policy coherence}

The development business has had a longstanding problem of goal displacement. In 1955 W. Arthur Lewis (1955) noted that economic growth was not the purpose of development, rather it was a means to increase the choices available to people. But for years, economic growth has been the de facto goal driving much development practice with marginal attention paid to whether it was increasing the choices available to people; still less, whether it was increasing meaningful choices for all citizens. The Millennium Declaration has represented one example of a major corrective for this tendency of goal displacement and the MDGs have provided some degree of policy coherence around a focused goal of poverty reduction. Although the MDGs are underpinned broadly by a human development agenda (see Hulme in this IDS Bulletin for a discussion), it can be argued that they are not underpinned by a coherent conceptual framework that includes a pathology or theory of how to achieve them (Saith 2007). This reduces their ability to support a coherent body of action that works to achieve the main goal that they aim for.

In short, the MDGs may give us an idea of where we want to go, but they do not say much about how to get there. In other words, although it means that everyone is talking about a commitment to poverty reduction, the MDG framework permits a promiscuous approach to what is to be valued as an appropriate course of policy and action and how that is to be realised in practice. It is this promiscuity that provides the policy space for development practice to continue with 'business as usual', where many of the types of projects and programmes after the MDGs do not differ significantly from those of before. For some observers, the most telling Indicator of 'business as usual' is the persistence of widespread poverty even after ten years of MDG effort.

This problem of better defining the purpose of development is now widely recognised and has been a key message of Amartya Sen's arguments favouring ethical over instrumental rationality.
Robert Chambers, too, has argued that it is important to conceive of development as 'good change' and therefore to give content to what it is we expect development to achieve (1997). The revived debate around human wellbeing has generated considerable consensus around the view that the fundamental purpose of development policy is to provide the societal conditions for human flourishing and to attack those conditions that produce human suffering. This suggests that promoting human wellbeing should be regarded as the first order issue for development policy and practice and that routes to achieving this, whether those be promoting economic growth or arranging redistribution, etc. are then second order considerations. From this perspective, the first question to ask of any development policy or programme is 'Does it promote human wellbeing?'

Nevertheless, there is a common tendency among those deeply involved in the development field to assume a much greater level of agreement about the idea of development than is observable in reality. This lies at the root of much development policy incoherence. Looking at recent experiences of development and societal change we can observe many different patterns of development around the world: it can entail economic growth accompanied by welldistributed human development benefits; it can entail growth accompanied by widespread inequalities in human development benefits. It may be a form of societal change that is highly destructive of the natural environment or a form that is relatively benign in its impact of natural resource endowments. For some countries, we may still observe that the experience of development has been akin to what used to be called 'underdevelopment', which involves the development of patterns of relationships that deliver few benefits for their populations but increase their dependence on other world systems and powers. However, not all of these patterns of development enable or support all people to achieve wellbeing and many of them do little to particularly support poor people to overcome the forms of illbeing that are manifest in their poverty. Some patterns of development may even result in conditions which make it much harder for some people to achieve wellbeing. This is possible because not all notions of what development should be and how that can be promoted are focused on improving the 
societal conditions for human wellbeing of all members of society. Rather they are focused on development as some other objective or vision of what it is to be 'developed' (to have a high per capita income, to be modern), in the belief or on the assumption that human wellbeing will somehow magically follow.

By seeking to focus our attention on the conditions in societies that enable human flourishing, the concept of human wellbeing presents itself as a potential mechanism for encouraging greater policy coherence. The contemporary policy literature is well aware of the costs and problems of incoherence and the quest for 'coherence' is a recurrent theme in recent major policy statements (see, e.g. EC 2005). As we have argued, while the MDGs have offered some basis for coherence, they lack an underlying conceptual framework which would provide broader policy guidance for coherence. Since the human wellbeing approach does not focus solely on poverty and it encourages us not to treat poor people as an isolable section of society, a focus on human wellbeing begins to weaken the separation of development and poverty policy from other dimensions of public policy. In this view, all public policy is germane to the maintenance and promotion of human wellbeing. The questions for policy agenda then become: what instruments of policy are most effective in promoting human wellbeing; whose wellbeing must be prioritised; and how can wellbeing be promoted globally in a sustainable manner. By promoting this type of agenda, a focus on human wellbeing provides greater potential as a focus for policy coherence. It encourages an exploration of development policy in relation to other policy spheres, such as trade, environment or security policy, all of which have considerable significance for the prospects of wellbeing for poor people around the world. Equally, through its emphasis on the relational dimension of wellbeing, it encourages politicians and policy thinkers to recognise the interconnectedness of the wellbeing of people in developing countries with the wellbeing of people in the developed world. ${ }^{4}$

\section{What does human wellbeing offer for the specifics of MDG policy and practice?}

While this broad level contribution of a 3-D human wellbeing framework is important, the further challenge if we are to move beyond 'business as usual', is to consider what a focus on human wellbeing offers in practical terms for development policy and practice. This 3-D framework recognises that all three perspectives are important in human lives and it follows then that development initiatives must also explore the ways in which they address all three dimensions. This means that we must work to develop indicators of each of the three dimensions and find ways of integrating these into development policy design as well as into monitoring and evaluation systems. The indicators that flow from this definition are broader and sometimes different from those that we currently depend on in development practice. Income-based indicators or the human development index deal only with one part of the objectively observable (or reportable) dimensions of human wellbeing, while this definition requires us to go further to take account of whose needs are being met, alongside who is able to act meaningfully in pursuit of their goals and for these to be considered, taking account of people's own evaluations of how well they are doing in their lives.

The approach also offers us a way to consider what types of policies and interventions might be pursued. Analysis using this approach suggests that wellbeing arises from the interaction of the capabilities of the person and the societal conditions in which they struggle to escape persistent illbeing outcomes. It emphasises that capabilities and conditions cannot be considered in isolation from each other and wellbeingfocused development policy will usually require action that works on both human capabilities and societal conditions at the same time. Historically, development interventions have mirrored a controversy which lies at the heart of social science debate, which is whether to emphasise either agency or structure at the expense of the other, but the argument here is for a policy approach that takes account of both.

In Table 2, we use the 3-D wellbeing framework to construct a simple matrix to illustrate the types of analysis and policy choice for each of the three dimensions when considering 'capabilities' and 'conditions' dimensions of possible interventions. Thus, for example, when we consider how to improve the material wellbeing of dimensions of the population it is important not only to consider establishing credit programmes but also whether market reform 
Table 2 Wellbeing, capabilities and conditions: policy interventions for 3-D human wellbeing

\begin{tabular}{llll}
\hline $\begin{array}{l}\text { Dimensions of wellbeing/ } \\
\text { types of intervention }\end{array}$ & Material & Relational & Subjective \\
\hline Capabilities interventions & $\begin{array}{l}\text { Asset transfer schemes. } \\
\text { Credit and savings } \\
\text { schemes (e.g. MDG 1). }\end{array}$ & $\begin{array}{l}\text { Human and skills } \\
\text { development schemes. } \\
\text { Empowerment programmes } \\
\text { (e.g. MDG 2). }\end{array}$ & $\begin{array}{l}\text { The social and cultural } \\
\text { dimensions of education } \\
\text { programmes (e.g. MDGs 2, } \\
\text { 3, 5, 6). }\end{array}$ \\
Conditions interventions & $\begin{array}{l}\text { Land reform. } \\
\text { The regulation of } \\
\text { markets (e.g. monopoly } \\
\text { regulation, money } \\
\text { lending, trading weights } \\
\text { and measures). }\end{array}$ & $\begin{array}{l}\text { Legal reform. } \\
\text { Gights-based approaches. }\end{array}$ & $\begin{array}{l}\text { Societal campaigns for } \\
\text { social and cultural reform } \\
\text { (e.g. dowry campaign, } \\
\text { anti-discrimination policies). }\end{array}$ \\
& & &
\end{tabular}

policy is also necessary to ensure that any credit received is not immediately eroded by unfair market conditions in which poor people might operate. Equally, thinking along the rows it may be necessary to consider whether any credit schemes must also be accompanied by skills development inputs that ensure the value added from accessing credit is increased. This of course is familiar in terms of being a form of integrated development, but what is important here is the proposition that the decisions about what elements are to be integrated depends upon an analysis which is hinged around the goal of seeking sustained human wellbeing improvements.

This type of human wellbeing analysis suggests that the MDGs and public policy should continue to place emphasis on material wellbeing (public expenditure, growth, etc.) but that these efforts should not displace attention to less conventional public policy domains around relational and subjective wellbeing and thus values, relationships, norms and behaviour.

The possibility of public policy paying greater attention to these spheres has been highlighted by recent contributions from Ariely (2008), Thaler and Sunstein (2008) and more broadly in Behavioural Economics. ${ }^{5}$ These writers challenge 'the notion that each of us thinks and chooses unfailingly well' (Thaler and Sunstein 2008: 6). Human beings are recognised as being influenced by their context and as responding to their 'choice architecture' or the organisation of that context in which people make their decisions (Thaler and Sunstein 2008: 3). This approach then flirts explicitly with the notion of 'libertarian paternalism', i.e. public policy to influence choices or decisions (but not by coercion) or 'nudge' people 'in a way that will make the choosers better off, as judged by themselves' (Thaler and Sunstein 2008: 5). This is dangerous territory for public policy but is unavoidable if we are to take subjective dimensions of wellbeing seriously and at the same time recognise the ways that power operates to shape wellbeing perceptions and strategies. While dangers of paternalism are apparent it can also be balanced by a view that if logic of 'nudge' is accepted, then we need also to have stronger democratic arrangements that permit genuine debate and deliberation which places expert views in their proper context as an input into inclusive processes of decision-making.

A fundamental observation from applying this approach to human wellbeing in analysis is that an essential element of the societal conditions for human wellbeing is the creation and promotion of organisations and institutions which enable people to pursue their notion of wellbeing, in reasonable ways: that is, in ways that do not inflict harm on others (Deneulin and McGregor 2009). It provides us with a way of analysing the role of institutions which have so often represented the 'black box' of development thinking. If we interpret poverty from this wellbeing perspective - poverty occurs where some people have neither the resources nor the power to achieve even the most basic levels of wellbeing and where societal institutions fail to 
protect or support them in their efforts to do so. A focus on human wellbeing tells us that development policy and practice must better recognise and deal with the capabilityinstitutions interactions that arise from heterogeneity among human beings. And the approach highlights that systems of governance are key to coping with that heterogeneity in a way that is constructive for human wellbeing.

\section{Conclusions}

There is more to human wellbeing than it simply being a new label for development itself. It potentially stands at the heart of the argument for a new human-centred paradigm for development thinking. Refocusing development on human wellbeing offers a way of critically reflecting on the adequacy of our currently accepted wisdom about how we think about and do development.

First, it points out that a state of wellbeing is something that people (you and I) struggle for and achieve (or fail to achieve) for themselves. Wellbeing cannot be delivered directly to people by governments, non-governmental organisations (NGOs) or other development agents, yet many development agencies continue to operate with an implicit view that they do deliver wellbeing. Agents can create enabling environments with capability and condition interventions such as those discussed above. At the same time, some may argue that a focus on wellbeing is too personal a subject for public policy bodies and it may appear to provide license for government meddling too much in the personal dimensions of peoples' lives, but this belies the fact that many examples of current and conventional development practices often involve implicit assertion of notions of wellbeing. These are embedded in their conception of development and most often pay little heed to the conceptions of wellbeing of the people in whose name development funding is mobilised and spent (Bebbington et al. 2007).

Second, the 3-D wellbeing approach builds on the recognition of the multidimensional nature of poverty and then provides a coherent framework in which to comprehend the complexity that flows from those observations. Acknowledging the general wave of dissatisfaction with current, disciplinarist social science approaches to real world policy problems, the wellbeing approach provides a way of exploring a more complex form of understanding human behaviour and development that is policy relevant.

Third, the wellbeing approach highlights the significance of difference: people differ from each in terms of their capabilities and their position in society from which to exercise these. What you are trying to achieve in your life and what I am trying to achieve may be different and we may choose different ways of trying to achieve that, but we still have to live together in society (Deneulin and McGregor 2009). While much lipservice has been paid to difference (or heterogeneity), both academia and development practice have struggled to find ways to cope with it in making policy coherent and effective for poverty reduction.

It could be argued of course that the increased poverty focus of many development agencies and governments over the last 15 years or so has also acted as a mechanism for coherence in the way discussed here, but the increasing proliferation of different 'poverties' or dimensions of poverty means that the poverty focus can now be highly diffused. Moreover, the poverty focus is also essentially negative and as such, often stymies strands of development thinking that are more focused on positive visions of development. Having wellbeing as a central organising goal will not in itself solve the problem of coherence; that is a broader challenge to political and policy agents. Nor does it supplant all other policy objectives, but it could go some way to providing us with a way of teasing-out wellbeing clashes and conflicts across different policy spheres.

The Millennium Declaration has provided considerable impetus to refocus the efforts of development agents around the world on the major moral challenge of eradicating global poverty. The MDGs that followed from it then have become an important mechanism. A concept of 3-D human wellbeing can contribute to a revived MDG momentum if development policy complements its emphasis on material wellbeing by placing it in relation to relational and subjective dimensions of human wellbeing. This will mean more attention on how these three dimensions relate in the spheres of human values, relationships, norms and behaviours. 


\section{Notes}

1 For example, the improvements in primary enrolment in Africa have coincided with a deterioration of the teacher-student ratio (ACPF 2008: 29; Mekonen, this IDS Bulletin).

2 The Wellbeing in Developing Countries Research Group (WeD) at the University of Bath was funded by the UK Economic and Social Research Council (ESRG) to develop a conceptual and methodological approach for understanding the social and cultural construction of wellbeing in developing countries.

\section{References}

ACPF (2008) The African Report on Child Wellbeing: How Child-friendly are African Governments?, Addis Ababa: The African Child Policy Forum Appadurai, A. (2004) 'The Capacity to Aspire: Culture and the Terms of Recognition', in V. Rao and M. Walton (eds), Culture and Public Action, Stanford: Stanford University Press: 59-84

Ariely, D. (2008) Predictably Irrational: The Hidden Forces that Shape our Decisions, London: HarperCollins

Bebbington, A.; Hinojosa-Valencia, L.; Munoz, D. and Lizarazu, R. (2007) 'Livelihoods and Resources Accessing in the Andes: Desencuentros in Theory and Practice', in I. Gough and J.A. McGregor (eds), Wellbeing in Developing Countries: From Theory to Research, Cambridge: Cambridge University Press

Bourguignon, François; Bénassy-Quéré, Agnès; Dercon, Stefan; Estache, Antonio; Gunning, Jan Willem; Kanbur, Ravi; Klasen, Stephan; Maxwell, Simon; Platteau, Jean-Philippe and Spadaro, Amedeo (2009) Millennium Development Goals at Midpoint: Where do We Stand and Where do We Need to Go? Paris: Cientre for Economic Policy

Camfield, L.; Woodhead, Martin and Streuli, N. (2008) Children's Well-being in Contexts of Poverty: Approaches to Research, Monitoring and Participation, Young Lives Technical Note 12, Oxford: Young Lives Project

Chambers, R. (1997) 'Editorial: Responsible Well-being - A Personal Agenda for Development', World Development 25.11: 1743-54

Deneulin, S. and McGregor, J.A. (2009) 'The Capability Approach and the Politics of Social Wellbeing', WeD Working Paper 09/43, University of Bath, www.welldev.org.uk/
3 Children are defined by UNHCR as below the age of 18. For greater discussion of application of a wellbeing approach and children, see in particular Camfield et al. (2008) and Sumner et al. (2009).

4 See Chambers' (1997) notion of 'responsible wellbeing' and, of course, climate change now provides the starkest example of why this should be the case.

5 Cass Sunstein is President Obama's confirmed Head of the Office of Information and Regulatory Affairs.

wed-new/workingpapers/workingpapers/

WeDWP_09_43.pdf (accessed 6 October 2009)

EC (2005) The European Consensus on Development, Brussels: European Commission

Gough, I. and McGregor, J.A. (eds) (2007) Wellbeing in Developing Countries: From Theory to Research, Cambridge: Cambridge University Press

Kahneman, D.; Diener, E. and Schwarz, N. (2003), Well-Being: Foundations of Hedonic Psychology, New York: Russel Sage Foundation

Layard R. (2006) Happiness: Lessons from a New Science, London: Penguin

Lewis, O. (1996) 'The Culture of Poverty', reprinted in G. Gmelch and W. Zenner (eds), Urban Life: Readings in Urban Anthropology (1988), Prospect Heights: Waveland Press

Lewis, W.A. (1955) The Theory of Economic Growth, London: Allen \& Unwin

McGregor, J.A. (2007) 'Researching Wellbeing: From Concepts to Methodology', in I. Gough and J.A. McGregor (eds), Wellbeing in Developing Countries, Cambridge: Cambridge University Press

OECD, Measuring the Progress of Societies. Ongoing, www.oecd.org/progress (accessed 6 October 2009)

Redmond, G. (2008) Children's Perspectives on Economic Adversity: A Review of the Literature, Discussion Paper 2008-01, Florence: UNICEF Innocenti Research Centre

Saith, A. (2007) 'From Universal Values to MDGs: Lost in Translation', Development and Change 37.6: 1167-99

Sarkozy Commisison (Stiglitz, J.; Sen, A. and Fitoussi, J.) (2009) Report of the Commission on the Measurement of Economic Performance and Social Progress, Paris, www.stiglitz-sen-fitoussi.fr/ documents/rapport_anglais.pdf (accessed 12 November 2009) 
Sen, A. (1999) Development as Freedom, Oxford: Oxford University Press

Sumner, A.; Haddad, L. and Gomez-Climent, L. (2009) 'Rethinking Inter-Generational

Transmissions: Does a Wellbeing Lens Help?', IDS Bulletin 40.1: 22-30
Thaler R. and Sunstein, C. (2008) Nudge: Improving Decisions About Health, Wealth and Happiness, Newhaven and London: Yale University Press

UNICEF (2005) State of the World's Children, New York: United Nations Children's Fund 